\title{
In vitro Determination of Antibacterial Effect of Garlic (Allium sativum) on Staphylococcus aureus and $E$. coli
}

\author{
Manu Yadav*, Rachna Bohra, Nidhi Gupta
}

Industrial Estate, Shahibabad Ghaziabad-201010, Uttar Pradesh, India

*Corresponding author

\section{A B S T R A C T}

\section{Ke ywords \\ Garlic (A. sativum), staphylococcus aureus, E. coli, Antibacterial activity \\ Article Info \\ Accepted: \\ 04 August 2019 \\ Available Online: \\ 10 September 2019}

The present study was conducted to test anti -bacterial activity of garlic against Staphylococcus aureus and Escherichia coil. The antibacterial effects of Aqueous Garlic Extract (AGE) against gram-positive and gram-negative bacterial isolates, Staphylococcus aureus and Escherichia coli were studied. Antibacterial activity of different concentrations of Aqueous Garlic Extract (AGE) by Well- Diffusion Method. Garlic extract was used in the range of $100 \%$ to $5 \%(1 \mathrm{ml} / \mathrm{mL}, 0.5 \mathrm{ml} / \mathrm{ml}, 0.25 \mathrm{ml} / \mathrm{ml}, 0.125 \mathrm{ml} / \mathrm{ml}$ and 0.625 $\mathrm{ml} / \mathrm{mL}$ ), against Staphylococcus aureus and Escherichia coli respectively. Further analysis revealed the antimicrobial efficacy of Aqueous Garlic Extract (AGE) is time and temperature dependent. These results suggest that garlic have anti -bacterial activity against Staphylococcus aureus and Escherichia coli and can be used against pathogenic microorganisms.

\section{Introduction}

Test item: Garlic (Allium sativum)

\section{Garlic}

Allium sativum is a scientific name. it is commonly known as garlic is an odoriferous plant belonging to a Lilacease family. Garlic is a common plant and easily provides the market. (Gaekwad et al., 2013) It is a small perennial herb with narrow flat leaves and is confined all sides by membranous patches, garlic grown mostly in Northern Nigeria. The medicinal property of garlic due to its
"Sulphur" content which was believed to be responsible for it is medicinal value. Raw garlic is used to treat colds and coughs. Garlic is an herbal ingredient for lowering high blood pressure Fighting heart alignments and cholesterol. It is used mainly for spice and also for its medicinal property (Lawnson and Bauer et al., 1989).

Garlic is our good because Garlic is rich in compounds like Allicin, Sulphur, Zinc, and Calcium that have health benefits, beauty benefits as well as antibiotics and antifungal properties. 
It is also a rich source of selenium. Selenium is known to fight cancer and it works with vitamin $\mathrm{E}$ in the body to boost antioxidant powder.

Garlic as a medicinal plant has been widely used and found to be very effective of infections Other plants like the ones mentioned earlier also have their medicinal properly, some which is as a result of the presence of alkaloids, volatile oils, polyphenol and some related Sulphur compound contained in them. Similarly, some are found to be used as vermifuge, stimulating carminative toxic and also as condiments and also as condiments and for treatment of worm bites just like garlic. Garlic is a mostly useful for medicinal, and control to infections. Garlic has been used from the time when ancient times in India and China for a valuable effect on the heart and circulation, cardiovascular disease and regular use of garlic may help to prevent cancer, to treat malaria, and to raise immunity. Garlic has also proposed to treat asthma, candidiasis, colds, diabetes, and antibacterial effect against food borne pathogens like $S$. aureus.

Therapeutic use of garlic has been recognized as a potential medicinal value for thousands of years to different microorganisms. For example; antifungal, antiviral, antibacterial, antiseptic and anti-inflammatory properties of garlic are well documented. Furthermore, garlic extracts exhibited activity against both gram negative (E. coli, enterobacter, Pseudomona, kilabsella) and gram positive ( $S$. aureus, S. pneumonia, streptococcus and Bacillus anthrax) all of which are cause of morbidness universal. This study will focus on recently research on protective effects of garlic against Staphylococcus aureus. There is extensive literature on the antibacterial effects of fresh garlic juice, aqueous and alcoholic extracts, and other commercial preparations of garlic.

\section{Escherichia coli}

Escherichia coli belongs to a group of bacteria informally known as coliforms that are found in the gastrointestinal tract of warm-blooded animals. E. coli is a Gram- negative bacteria because its cell wall is composed of a thin peptidoglycan layer and an outer membrane. It is a facultative anaerobic, rod shaped (1.1-1.5 $\mathrm{m}$ - 2.0-6.0 m), chemo-organotrophic microorganism, non-spore-forming, arranged in pairs or singly and coliform bacteria. The outer membrane surrounding the cell wall provides a barrier to foreseeable antibiotics such that $E$. coli is not damaged by penicillin. Optimum growth of $E$. coli occurs at $37^{\circ} \mathrm{C}$. E. coli is most widely used in study of prokaryotic model organism. E. coli is a important species in the field of biotechnology and microbiology Escherichia coli is oxidase negative, catalase positive, fermentative (glucose, lactose, D-mannitol), reduces nitrate, and is -galactosidase positive. Approximately $95 \%$ of E. coli strains are indole and methyl red positive, but citrate is negative. Although most strains of $E$. coli have been described as harmless commensal organism, they can be versatile pathogens in immune compromised patients. The organism is an inhabitant of the human digestive tract and can also be found in other warm blooded animals. Most strains of E. coli is not harmful bacteria but this part of the healthful bacterial flora in the human gut.

E. coli has been used as an indicator of fecal contamination in food and water due to its common occurrence in feces and its survival in water. Antibiotics generally aren't suggested because they can be increase the risk of serious complicatedness. If you have a serious E. coli infection that has caused hemolytic uremic syndrome. The limits of temperature for growth of $E$. coli are $7-46^{\circ} \mathrm{C}$, and the optimum growth temperature is approximately $37^{\circ} \mathrm{C}$. E. coli generally grows within the $\mathrm{pH}$ range of 4.4-9.0 and at $\mathrm{NaCl}$ levels of less 
than $8.5 \%$. E. coli can be recovered easily from clinical specimens on general or selective media at $37^{\circ} \mathrm{C}$ under aerobic conditions (Lawn et al., 1997).

\section{Staphylococcus aureus}

Staphylococcus aureus is mostly 14 strains species. S. aureus is Gram-positive coccus shaped microorganism (with diameter of between $0.7 \mathrm{~m}$ to $1.2 \mathrm{~m}$ ) that generally occurs in grape-like clusters but can also be found in singles and pairs. Cells are non motile, lack flagella and do not form spores, though they are able to survive in dormant state for years under unfavorable conditions. Staphylococcus aureus grows best under aerobic conditions but can employ a fermentative metabolism, making it a facultative anaerobe. The organism can utilize several different carbohydrates during respiration.

However, under anaerobic conditions, $S$. aureus will typically ferment glucose resulting in the production of lactic acid and ability to ferment mannitol. The great herbalists and physicians of the ancient world record garlic historical use. "Garlic has powerful properties medicines of skin infections.

The present study tested an aqueous extract of dried garlic for its antibacterial activity against Staphylococcus aureus and E. coli. ( Foster, Koch et al., 1996, 97).

\section{Garlic as an antibiotic}

Garlic is an anti -bacterial agents that can actually inhibits growth of infectious agents and at the same time protect the body from the pathogens.

It is known that the most sensitive bacterium to garlic is the deadly Bacillus anthracis which causes the diseases anthrax.
Even the father of antibiotic medicine Louis Pasture honour garlic to be an effective antibiotic. Some years later garlic was shown to have similar effect/activity as ampicillin. (Panel Serge Ankri David Mirelman et al., 1999).

\section{Pathogenic microorganisms}

Microorganisms that cause disease are called pathogens. The invasion of the body by the pathogenic organisms is called infection. The immune system of a person may be able to prevent multiplication, spread and establishment of the pathogen and resist the effects of a toxin in the tissue. Not all infection leads to disease. Gram negative bacteria cause infections including pneumonia, blood stream infection, wound or surgical site infections, and meningitis in healthcare setting.

\section{Materials and Methods}

\section{Materials and Methods}

\section{Culture media}

Culture media are prepared according to the produce by companies instruction and then sterilized in autoclave at $196^{\circ} \mathrm{F}$ under pressure of 15PSI after incubation at $37^{\circ} \mathrm{C}$ for 28 hours, used for culture and identify of effectiveness of bacteria against garlic.

\section{Preparation of plant}

Garlic was collected from the local market and established as natural Allium sativum.

\section{Extraction methods}

Fresh garlic (Allium sativum L.) bulbs were purchased from local market. Garlic bulbs were peeled, weighed (150 g), and cleaned. Cleaned cloves were surface -sterilized by 
immersing them into $70 \%$ ethanol. Residual ethanol on surface was evaporated in sterile laminar airflow chamber followed by homogenizing aseptically in sterile mortar and pestle. The homogenizing mixture was filtered through a sterile muslin cloth. This extract considered as the $100 \%$ concentration of the extract. Filtrate was considered $100 \%$ fresh garlic extract, was stored at $-20^{\circ} \mathrm{C}$, and was thawed before use. One hundred fifty grams of raw garlic yielded $9 \mathrm{ml}$ of juice. Each time $100 \%$ garlic juice (undiluted) was inoculated on nutrient agar media and incubated at $37^{\circ} \mathrm{C}$ overnight and was found to be sterile. The concentrated $(100 \%)$ juice was further diluted to $10-25 \%, 50 \%$ by mixing with appropriate sterile distilled water (Davis et al., 2009).

\section{Microorganisms used}

A total of one Gram negative and one Gram positive organisms were used in this study. The isolates Escherichia coli and Staphylococcus aureus were obtained from the culture collection of Dabur Research Foundation, Shahibabad.

\section{Antimicrobial activity used}

The antibacterial activity of the crude extracts was determined in accordance with the agar well diffusion method against the test bacteria isolates.

Eighteen hours broth cultures were diluted appropriately using McFarland scale. The molten sterile Muller Hinton Agar (MHA) was poured into sterile petri dish and allowed to set.

The sterile MHA plates were flooded with $0.1 \mathrm{ml}$ of the standardized inoculum.

One drop of the molten agar was used to seal the bottom of the bored hole, so that the extract will not sip beneath the agar. Approximately 50 microliter of the extract at different concentrations was introduced into the wells.

A control was prepared by putting 50 microliter of freshly prepared sterile distilled water in one of bored hole at the plates containing aqueous suspensions where 50 microliter of methanol use at the plates containing methanolic suspensions.

One hour pre- diffusion time was allowed, after which the plates were incubated at $37^{\circ} \mathrm{C}$ for $18 \mathrm{~h}$. The zones of inhibition were then measured in millimeter (mm). The above method was carried out in replicates and the mean of the replicates results were taken $(\mathrm{Li}$, et al., 2015).

\section{Preparation of standard inoculum}

Pure colonies were picked up with the help of a sterilized inoculation loop and emulsified in a test tube containing saline. The turbidity was matched with $0.5 \%$ McFarland standard containing $1 \times 10^{7}$ (count forming unit) $\mathrm{CFU} / \mathrm{ml}$ approximately.

\section{Well diffusion method}

Mueller Hinton Agar (MHA) was poured in plates of $90 \mathrm{~mm}$; depth of agar was 3-4 mm. With sterile cotton swab, the test culture was spread evenly over the plate successively in three directions to obtain an even inoculum.

The plates were allowed to dry for 3-5 min. Wells of $5 \mathrm{~mm}$ diameter were cut on the surface of the agar.

$50 \mu 1$ of $5 \%, 10 \%, 25 \%, 50 \%$, and $100 \%$ solutions $(\mathrm{v} / \mathrm{v})$ of fresh garlic juice was added to different wells and in one well, normal saline was added. The plates were incubated at $37^{\circ} \mathrm{C}$ for $22 \mathrm{~h}$. The zone of inhibition was measured by a scale to the nearest $\mathrm{mm}$ including disc diameter. 
Isolation of Staphylococcus aureus and $E$. coli

Agar plates were inoculated with $0.01 \mathrm{ml}$ of Staphylococcus aureus suspension which was clearly grown on MHA (McFarland 3) and incubated for $18-24$ hours at $35-37^{\circ} \mathrm{C}$ under aerobic condition.

Antibacterial effect of garlic on Staphylococcus aureus and E. coli

Susceptibility of Staphylococcus aureus was determined by the agar dilution method using Muller Hinton agar (The Modified KirbyBauer susceptibility testing technique).

Clearly prepared garlic fresh juice the concentration was determined with varying amounts of crude preparation of garlic to give the final concentration 5\% media (Mohamed A. Eltaweel et al., 2004).

\section{Results and Discussion}

\section{Identification of bacteria}

The bacteria grow well on Muller Hinton Agar (MHA).

Microscopic examination for Staphylococcus aureus: - Gram-positive, round shape (Fig. 1).

Microscopic examination for E. coli:- Gramnegative, rod in shape (Fig. 2).

Fresh garlic juice was tested against $S$. aureus and $E$. coil using agar well diffusion method and results of the zone of inhibition at different concentration of fresh garlic juice are evaluated in Table 1 and 2.

The inhibitory effect of garlic extracts well diffusion method

The sensitivity of the previously mentioned bacteria gradually increased with the increment of concentration of extract. The zone of the inhibition was $90 \mathrm{~mm}$ was for the concentration of $90 \mathrm{~mm}$ was for the concentration $100 \%$. The concentrations $5 \%$ were rather low active in preventing the growth of Staphylococcus aureus, the concentrations $10 \%-25 \%$ were moderate active, while the concentrations 50\%-100\% were highly active compared to ethylene glycol as a control evaluated in Table 1 and Figure 3 and 4.

There was a proportional relation between the concentrations of extract and the diameters of inhibition zones of the growth of Staphylococcus aureus and E. coli.

E. coli zone of inhibition in positive control (ampicillin) was $50 \mathrm{~mm}$ and in negative control (distilled water) it was $0 \mathrm{~mm}$.

E. coli zone of inhibition in garlic extract concentrations at $100 \%, 50 \%, 25 \%, 10 \%$ and $5 \%$ was $34 \mathrm{~mm}, 27 \mathrm{~mm}, 20 \mathrm{~mm}, 0 \mathrm{~mm}$ and $0 \mathrm{~mm}$ respectively.

Similar in case of $S$. aureus the zone of inhibition in positive control (ampicillin) was $70 \mathrm{~mm}$ and in negative control (distilled water) $0 \mathrm{~mm}$.

While of using garlic extract at concentrations in $100 \%, 50 \%, 25 \%, 10 \%$ and $5 \%$ was $37 \mathrm{~mm}$, $30 \mathrm{~mm}, 30 \mathrm{~mm}, 18 \mathrm{~mm}$ and no zone of inhibition.

All pathogenic bacteria showed statistically significant dose-dependent increase in the zone of inhibition at FGJ concentration of $10 \%$ and higher compared to control.

Ten percentage of FGJ showed $\geq 18 \mathrm{~mm}$ zone of inhibition in $S$. aureus and in E. coli $>0 \mathrm{~mm}$ zone of inhibition while $25 \%$ concentration of garlic juice showed $>30 \mathrm{~mm}$ of the zone of inhibition in $S$. aureus and in E. coli zone of inhibition $>20 \mathrm{~mm}$. 
Table.1 Zone of inhibition S. aureus at different concentrations using agar well diffusion method

\begin{tabular}{|c|c|c|}
\hline \multicolumn{3}{|c|}{ Staphylococcus aureus } \\
\hline S. No. & $\begin{array}{c}\text { CONCENTRATION (v/v) } \\
(\boldsymbol{\%})\end{array}$ & $\begin{array}{c}\text { ZONE OF } \\
\text { INHIBITIONS(mm) }\end{array}$ \\
\hline $\mathbf{1 .}$ & $\mathbf{5 \%}$ & 0 \\
\hline $\mathbf{2 .}$ & $10 \%$ & 18 \\
\hline $\mathbf{3 .}$ & $25 \%$ & 30 \\
\hline $\mathbf{4 .}$ & $50 \%$ & 35 \\
\hline $\mathbf{5 .}$ & $100 \%$ & 37 \\
\hline $\mathbf{6}$ & Positive control(ampicillin) & 70 \\
\hline $\mathbf{7 .}$ & Negative control & 0 \\
\hline
\end{tabular}

Table.2 Zone of inhibition on E. coli using different concentrations of garlic using agar well diffusion method

\begin{tabular}{|l|l|l|}
\hline \multicolumn{3}{|c|}{ E. coli } \\
\hline S. No. & $\begin{array}{l}\text { CONCENTRATION (v/v) } \\
\text { IN (\%) }\end{array}$ & $\begin{array}{l}\text { ZONE OF } \\
\text { INHIBITION(mm) }\end{array}$ \\
\hline $\mathbf{1 .}$ & $5 \%$ & 0 \\
\hline $\mathbf{2 .}$ & $10 \%$ & 0 \\
\hline $\mathbf{3 .}$ & $25 \%$ & 20 \\
\hline $\mathbf{4}$. & $50 \%$ & 27 \\
\hline $\mathbf{5 .}$ & $100 \%$ & 34 \\
\hline $\mathbf{6}$ & Positive control (ampicillin) & 50 \\
\hline $\mathbf{7 .}$ & Negative control & 0 \\
\hline & & \\
\hline
\end{tabular}

Fig.1 Result of gram staining Staphylococcus aureus

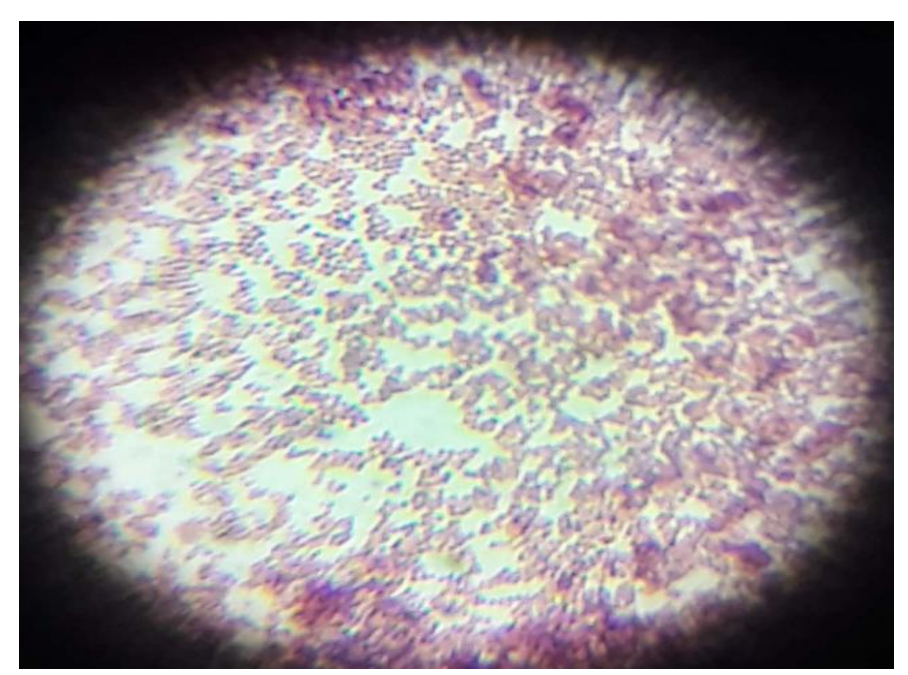


Fig.2 Result of gram staining E. coli

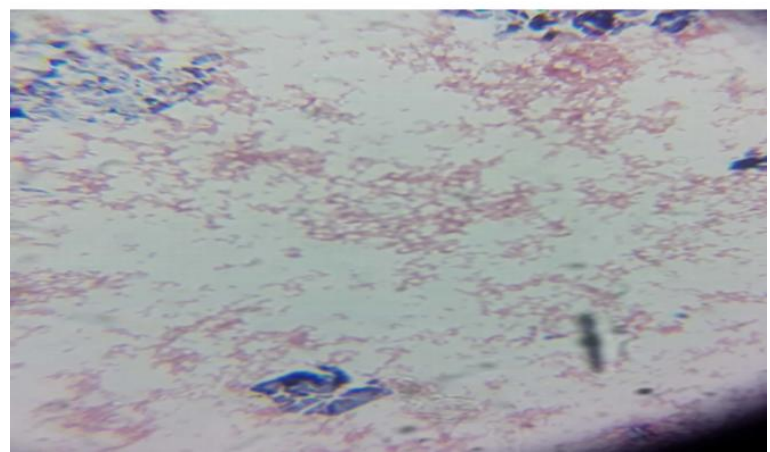

Fig.3 Zone of Inhibition Staphylococcus aureus at different concentrations using agar well diffusion method

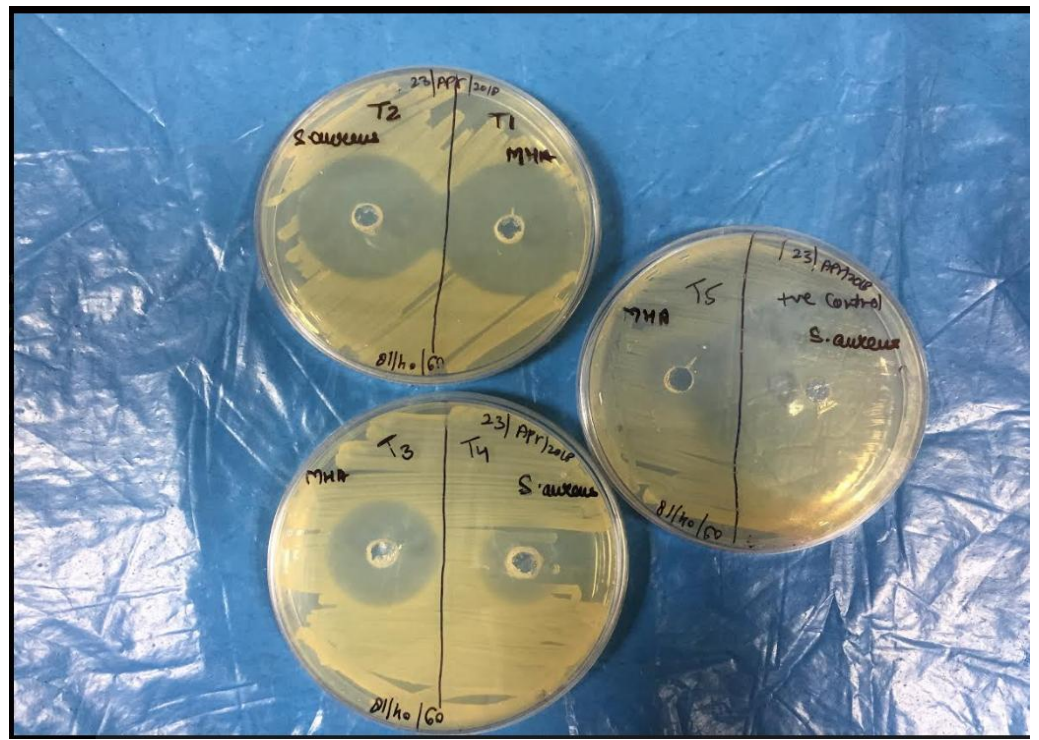

Fig.4 Zone of Inhibition E. coli using agar at different concentrations well diffusion method

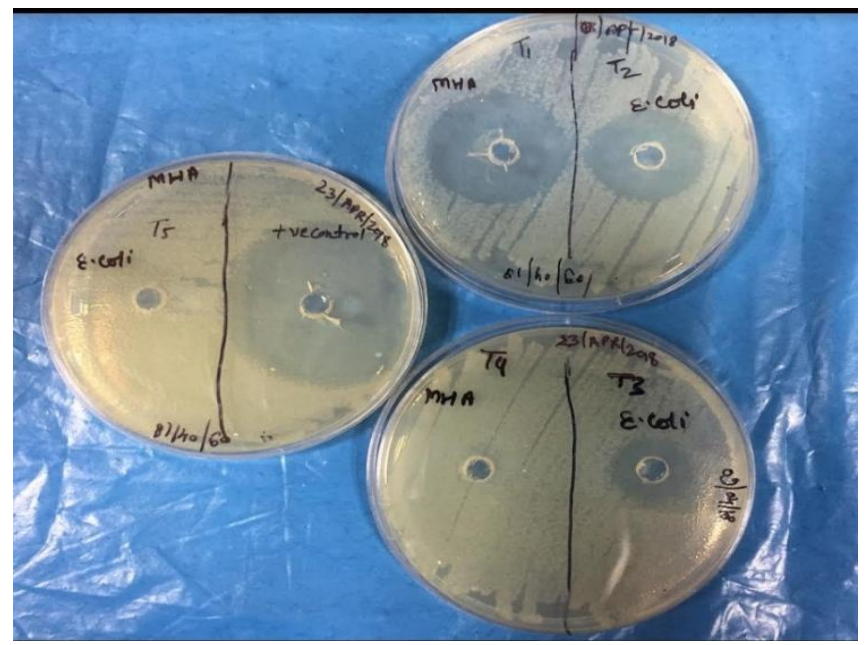


In this study, the Garlic possessed antibacterial effect of garlic against Staphylococcus aureus and E. coli was established. The sensitivity of the bacteria was increased with the increasing of extract concentrations (Table 1) Bacterial drug resistance is a world problem, a high number of bacterial species have become resistant to anti-bacterial (Ampicillin) drugs (Garau et al., 1994).

Thus, there is a need to evaluate the efficacy of garlic cloves and chemicals concerning with the growth important allicin in the gical stability of garlic aqueous extracts and their effects on both Gram positive (S. aureus) and Gram negative (E. coli) bacteria. Garlic is most effective against $S$. aureus compared to E. coli. S. aureus is a very sensitive bacterium to aqueous extracts of bacteria by extracts of garlic cloves to be used. These preparations are available to person for self-medication, with these- consideration the activity of Garlic extract on the growth of S. aureus and E. coli were studied. Microbial properties of garlic extract was due to pure allicin and was effective against many bacteria.

\section{Comparison}

Staphylococcus aureus is more effective as compare to Escherichia coli.

Staphylococcus aureus in maximum zone of inhibition.

In conclusion, this study features the significance of the raw garlic extract as an antimicrobial agent during in vitro bacterial infection. It has both a bacteriostatic and bactericidal activity. And in this study as per results and interpretation garlic was found effective against $s$. aureus and E. coli and may be used in various drug formulation against $S$. aureus and E. coli causes diseases for treatment because it is very more effective on bacteria and fungus. In addition the absence of bacterial resistance to garlic increases its capacity to effectively act against even highly resistance bacterial strains, such as $S$. aureus and E. coli.

Garlic aqueous extract has antibacterial properties against $S$. aureus and E. coli, garlic has antibacterial properties against other Gram positive and Gram negative bacteria.

This introductory screening study suggested that garlic used in classical medicine have potentials as antibacterial agents for a variety of Gram positive and Gram negative organisms. Garlic consuming of garlic may be utilizing as an economic way for patients and have been proposed as novel treatments of bacterial infectious disease also to reduce the problem of multi - drug resistant (Ampicillin) pathogenic bacteria.

\section{References}

Amir Sasan MozaffariNejad,1 Shahrokh Shabani: Antibacterial Effect of Garlic Aqueous Extract on Staphylococcus aureus in Hamburger Jundishapur $\mathbf{J}$ Microbiol. 2014 Nov; 7(11): e13134.

Ana Rita Costa, Deivid W. F. Batistão, Rosineide M. Ribas, Ana Margarida Sous, M. Olivia Pereira and Claudia M. Botelho. 1972. Staphylococcus aureus virulence factors and disease. Microbial pathogens and strategies for combating them: science, technology and education. 703-710.

Atheer Abdulhameed Khashan. 2014. Antibacterial activity of garlic extract (Allium sativum) against Staphylococcus aureus in vitro. G.J.B.B., 3 (4): 346-348.

Cavallito CJ, Bailey JH. Allicin, the antibacterial principle of Allium sativum L. Isolation, physical properties and antibacterial action. J 
Am Chem Soc. 1944; 66: 1950-1.

Davis SR, Perrie R, Apitz-Castro R. 2003. The in vitro susceptibility of Scedosporium prolificans to ajoene, allitridium and a raw extract of garlic (Allium sativum) $\mathrm{J}$ Antimicrob Chemother. 51, 593-597.

Deresse Daka. 2011. Antibacterial effect of garlic on Staphylococcus aureus: An in vitro study in 2009. African Journal of Biotechnology Vol. 10 (4), pp. 666669.

Nada Khazal Kadhim. Hindi. 2013. In vitro Antibacterial Activity of Aquatic Garlic Extract, Garlic Extract combination. American Journal of Phytomedicine and Clinical Therapeutics. 049-052.

Ellmore GS, Feldberg RS. Alliinlyase localization in bundle sheaths of garlic cloves Am J Bot. 81 (1): 89-94.

Gaekwad V, Trivedi NA. In vitro evaluation of antimicrobial effect of fresh garlic extract and its interaction with conventional antimicrobials against Escherichia coli isolates. Int J Curr Res Rev. 2013; 5: 106-14.

Jezowa L, Rafinski T, Wrocinski T. 2009. Investigations on the antibiotic activity of Allium sativum L. Herba Pol. Electronic Journal of Biology. 5(1): 5-10.

Lawn, A.M. 1997. Morphological Distinction of Escherichia coli. Journal of General
Microbiology, 101 (1): 111-119.

Rees, L. P., S.F. Minney, N.T. Plummer, J.H. Slater, D.A. Skyrme A quantitative assessment of the antimicrobial activity of garlic (Allium sativum) 1993 Vol. 9 issue 3

Li G, Ma X, Deng L, Zhao X, Wei Y, Gao Z, et al. 2015. Fresh garlic extract enhances the antimicrobial activities of antibiotics on resistant strains in vitro. Jundishapur J Microbiol. 6: 1-5.

Mohamed A. Eltaweel: Antibacterial Effect of Garlic (Allium sativum) On Staphylococcus aureus: An in vitro Study. African Journal of Biotechnology. 10 (4), pp. 666-669.

Nataro, J.P. and Kaper, J.BVarma, J. K. et al. Disease cause by E. coli 1998, 2003.

Panel Serge Ankri David Mirelman Review Antimicrobial properties of allicin from garlic Author links open overlay Volume 1, Issue 2, February 1999.

Feldberg, R., S. Chang, A. Kotik, M. Nadler, Z. Neuwirth, D. Sundstrom and N. Thompson.

Ryan KJ, Ray CG (editors) (2004). Sherris Medical Microbiology (4th ed.). McGraw Hill.

SeemaYadav, Niyati A. Trivedi, and Jagat D. Bhatt: Antimicrobial activity of fresh garlic juice: An in vitro study." AYU [An International Quarterly Journal of Research in Ayurveda], vol. 36, no. 2, 2015, p. 203.

\section{How to cite this article:}

Manu Yadav, Rachna Bohra and Nidhi Gupta. 2019. In vitro Determination of Antibacterial Effect of Garlic (Allium sativum) on Staphylococcus aureus and E.coli. Int.J.Curr.Microbiol.App.Sci. 8(09): 498-506. doi: https://doi.org/10.20546/ijcmas.2019.809.060 